\title{
A Review on the Relationship Between New Variables and Classical TAM Structure
}

\author{
Yuanquan Li, Jiayin Qi and Huaying Shu \\ School of Economics \& Management, Beijing University of Posts \& Telecommunications, \\ Beijing 100876, P.R. China Leo8410@gmail.com ssfajy@263.net shuhy@bupt.edu.cn
}

\begin{abstract}
Integration of different theories and expansion of research areas are the main trends in the research domain of IS adoption. Classical TAM structure has been largely expended by newly added variables. Prior studies [1] have analyzed relationships among variables in TAM and found the stability of classical structure, but what about relationships between new variables and classical structure? We selected $\mathbf{3 0}$ articles from the main international journals for analyses. It is found that, SE, SN and PBC are used mostly in extended TAM. The relations between SE, PBC and TAM are consistently significant, but the integration of SN into TAM is not so ideal. In our review scale, this relation is inconsistent. Other variables and relations are also discussed in this article. The conclusions of this article will provide guidance for future researches about extended TAM model building.
\end{abstract}

Keywords: TAM, TAM classical structure, New variables, Variable relations

\section{INTRODUCTION}

Although Information System (IS) has played an important role in modern enterprises, the implementation of IS is costly and has a relatively low success rate. Since the middle of 1980 s, researchers have begun to concentrate on predicting the effect of IS implementations by exploring user's adoption mechanism for IS. Among these researches, TAM (Technology Acceptance Model) is one of the most important models, which was proposed in the doctoral thesis of Davis (1986). With the development of nearly 20 years, TAM has become to be the mainstream model to explain the mechanism of IS adoption.

Based on different theories, many researchers have added some new variables into the classical TAM structure. For example, based on TPB (Theory of Behavior), Patrick Y.K. et al. added SN (Subject Norm) and PBC (Perceived Behavior Control) into TAM [2], S.-S. Liaw added PE (Perceived Enjoyment) by introducing SCT (Social Cognitive Theory) into TAM [3], and Chorng-Shyong Ong \& Jung-Yu Lai added CSE (Computer Self-Efficacy) depending on studies of Attribution Theory and Social Cognitive Theory [4].

Introduction of new variables into classical TAM has enhanced the explanatory power. However, the relations between new variables and classical TAM variables are inconsistent [5] and lack of relevant studies. In this article, we attempt to analyze

Please use the following format when citing this chapter:

Li, Y.. Qi, J., Shu, H., 2007, in IFIP International Federation for Information Processing, Volume 254. Research and Practical Issues of Enterprise Information Systems II Volume 1, eds. L. Xu, Tjoa A.. Chaudhry S. (Boston: Springer), pp. 53-63. 
these relations by reviewing previous studies and try to provide a reference for future research in IS adoption domain.

\section{CLASSICAL TAM STRUCTURE AND VARIABLES}

TAM was proposed by Davis in 1989 [6], two main variables are mentioned in the classical TAM (Figure 1): Perceived Ease of Use (PEOU) and Perceived Usefulness (PU). External variables have effects on Attitude toward Using (AT) and Behavior Intention (BI) through PEOU and PU, and finally affect the Use (U) of IS.

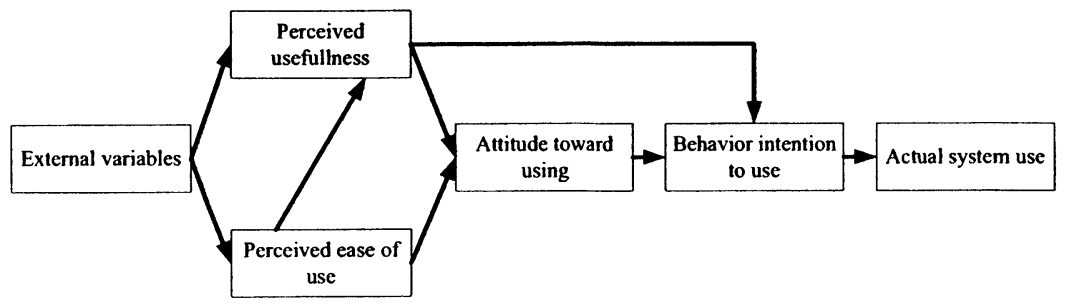

Figure 1. Classical Structure of TAM [6]

Different researchers in different researches used different TAM structures. They get extended models by adding some new variables or relations into classical TAM. However, we find most extended TAM models are still built on the classical TAM structure that is made by PU, PEOU, AT, BI and USE [1].

\section{NEW VARIABLES IN EXTENDED TAM}

In this research, the term 'new variables' is defined as the variables that do not exist in classical TAM structure but have initial theory supports, such as SN (based on SCT\&TRA), PBC (based on TPB). In our research, we only choose the new variables that be used widely and have theoretical supports. Depending on this criterion, we select Self-efficacy, SN (Subject Norm), Enjoyment, PBC (Perceived Behavior Control), Anxiety, Credibility, Compatibility, Innovation, Cost, Trust and Image which are described in the table below. 
Table 1. Explanation of New Variables

\begin{tabular}{|c|c|c|}
\hline & Explanation & Theory \\
\hline \multirow{3}{*}{ Self-efficacy } & $\begin{array}{l}\text { People are more likely to make internal attributions when } \\
\text { the event outcome is positive [7]. }\end{array}$ & Attribution Theory \\
\hline & $\begin{array}{l}\text { Self-Efficacy is composed by level of ability, intensity of } \\
\text { beliefs and generalizability of ability.[8] }\end{array}$ & SCT [8] \\
\hline & individual perceived ability to use computer.[10] & CSE [10] \\
\hline \multirow{2}{*}{ SN } & $\begin{array}{l}\text { Observed behaviors of others influence the observer to } \\
\text { emulate those behaviors. [8] }\end{array}$ & SCT $[8]$ \\
\hline & $\begin{array}{l}\text { Beliefs that specific individuals or groups approve or } \\
\text { disapprove of performing the behavior.[11] }\end{array}$ & $\begin{array}{c}\text { TRA [9] } \\
\text { TPB [11] }\end{array}$ \\
\hline Enjoyment & $\begin{array}{l}\text { The extent to which the activity of using the technology is } \\
\text { perceived to be enjoyable in its own right, apart from any } \\
\text { performance consequences that may be anticipated[12] }\end{array}$ & MM. [12] \\
\hline PBC & $\begin{array}{l}\text { Presence or absence of requisite resources and } \\
\text { opportunities [11] }\end{array}$ & TPB [11] \\
\hline Anxiety & $\begin{array}{l}\text { Computer anxiety was studied by Henderson et al. as an } \\
\text { element of the computer attitude scale (CAS) developed by } \\
\text { Loyd and Gressard [13]. }\end{array}$ & CAS[13] \\
\hline Credibility & Credibility can be simply defined as believability. [4] & \\
\hline Compatibility & $\begin{array}{l}\text { Compatibility refers to the degree to which an innovation is } \\
\text { perceived as consistent with the existing values, past } \\
\text { experiences and needs of potential adopters.[14] }\end{array}$ & DOI [14] \\
\hline Innovation & $\begin{array}{l}\text { Describes the extent to which the individual has an innate } \\
\text { propensity toward adopting a new IT [15]. }\end{array}$ & PIIT [15] \\
\hline Trust & $\begin{array}{l}\text { Trust is basically seen as a common mechanism for } \\
\text { reducing social complexity and perceived risk of } \\
\text { transaction[16] }\end{array}$ & $\begin{array}{l}\text { Social Exchange } \\
\qquad[16,17]\end{array}$ \\
\hline Image & $\begin{array}{l}\text { TAM2 theorized that subjective norm achieved its effect on } \\
\text { perceived usefulness partially by altering image.[18] }\end{array}$ & TAM2 [18] \\
\hline
\end{tabular}

In our research, we care about there types of relations between new variables and classical TAM structure, which are positive significant effect (marked as POS.), negative significant effect (marked as NEG.) and none significant effect (marked as NS.).

\section{RESEARCH METHODOLOGIES}

The literatures we select come from the journals as follows:

- MIS Quarterly;

- Decision Sciences;

- Management Science;

- Journal of Management Information Systems;

- Information Systems Research;

- Information \& Management;

- Journal of Information Technology;

- International Negotiation;

- Academy of Management Journal;

- Computer Standards \& Interfaces;

- Government Information Quarterly; 


\section{- Human-Computer Studies;}

\section{- Decision Support Systems}

The selected literatures were published from 1980s to 2006, and most articles are about model applications. These applications are not rigidly adhered to the fruits of predecessors, but creating many new improved models by combining other related theories. In summary, we get 108 articles. And further more, we choose 30 articles for analyzing based on the following three criteria: firstly, TAM is used in an empirical study; secondly, some new variables were added in the research model; finally, the research methodology is well described and the research results are available and complete.

\section{FINDINGS OF RESEARCH}

Through analyzing of literatures been selected, we get the results bellow:

Table 2. Relations between New Variables and Classical TAM

\begin{tabular}{|c|c|c|c|c|c|c|}
\hline New variables & & $\mathbf{P U}$ & PEOU & $\mathbf{A T}$ & BI & USE \\
\hline \multirow{3}{*}{ 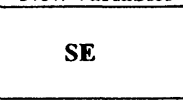 } & N.S. & & & & & 1 \\
\hline & NEG. & & & & & \\
\hline & POS. & 4 & 10 & & 4 & 1 \\
\hline \multirow{3}{*}{$\mathbf{S N}$} & N.S. & & & 2 & 4 & \\
\hline & NEG. & 2 & & & & \\
\hline & POS. & 1 & & & 9 & 1 \\
\hline \multirow{3}{*}{ PE } & N.S. & & 1 & 1 & 2 & \\
\hline & NEG. & & & & & \\
\hline & POS. & 1 & 3 & 4 & 3 & 1 \\
\hline \multirow[b]{2}{*}{ PBC } & N.S. & & & & 1 & 1 \\
\hline & POS. & & 4 & & 5 & 1 \\
\hline \multirow{2}{*}{ Anxiety } & N.S. & & & & & 1 \\
\hline & NEG. & 2 & 5 & & & \\
\hline Credibility & POS. & 2 & & 1 & 2 & \\
\hline \multirow{3}{*}{ Compatibility } & N.S. & 1 & & & & \\
\hline & NEG. & 1 & & & & \\
\hline & POS. & 2 & 4 & & 1 & \\
\hline \multirow{2}{*}{ Innovation } & N.S. & & & & & \\
\hline & POS. & 1 & 2 & 2 & & \\
\hline Cost & NEG. & & & 1 & 2 & \\
\hline Trust & POS. & & & 1 & 1 & \\
\hline Image & POS. & 1 & & 1 & 1 & \\
\hline
\end{tabular}

Notes: figures in the table above are the frequency this relation appears in our selected articles.

In order to describe the relations in the table above more clearly and easily understood, we design a structure below. In the center of this structure, that is classical TAM structure and around it that is 8 new variables. Cost, Trust and Image are not included in this structure, because these variables in our literature review are used seldom (less than 4 times). 


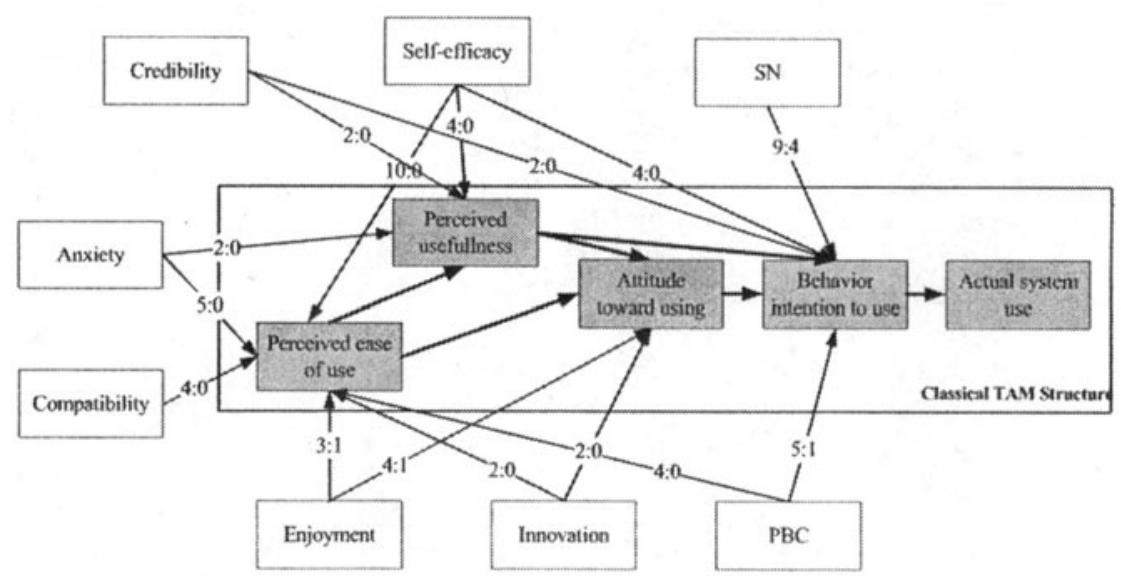

Figure 2. Relations between New Variables and Classical TAM

Notes: the left figure in the relation arrow means the number of significant relations; the right figure means the number of insignificant relations.

There exist consistent positive significant relations between Self-Efficacy and PU, PEOU and BI, no NEG. or N.S. effects were found. SN has 9 POS. relations with BI, but we also find 4 NEG. relations, so this relation is inconsistent, the SN-PU relation is all significant but lack of evidence to decide its effect type (POS. or NEG.). Relations between Enjoyment and PEOU and AT are consistent positive significant (POS.: N.S. is 3:1 and 4:1), but Enjoyment-BI relation is inconsistent (POS.:N.S. is 3:2). PBC has positive significant relation with PEOU and BI (POS.:N.S. is 4:0 and 5:1). Anxiety has significant negative relations with PU and PEOU (NEG.: N.S. is 2:0 and 5:0). Credibility has significant positive relations with PU and BI (POS.:N.S. is 2:0 and 2:0). Relation between Compatibility and PEOU is significant positive (POS.:N.S. is 4:0), but Compatibility-PU is inconsistent (POS.:NEG.: N.S. is 2:1:1).

Relations between Credibility, Innovation, Cost, Trust, Image and classical TAM are so fewer in our literature review scale that can not describe their relation types. So in this study these relations are not mentioned.

\section{DISCUSSIONS AND CONCLUSIONS}

The relations between $\mathrm{SE}$ and $\mathrm{PU}, \mathrm{PEOU}$ and $\mathrm{BI}$ are all positive significant in our results. Self-Efficacy refers to an individual's judgment of his or her ability to use a computer [10]. This may influence an individual's PEOU and acceptance. Such effects can also get theoretical support from the Self-Efficacy Theory. However, SE and PU relationship has been studied less in contrast to SE-PEOU and SE-BI, but in some special areas such as e-shopping [4], on-line tax [19] and broadband Internet 
[20], this relation has been mentioned in relevant hypothesis and empirical evidence shows a positive significant relation-ship between them.

SN-BI relation is inconsistent; the same results can also be got from previous studies. Jiayin Qi \& Yuanquan $\mathrm{Li}$ found SN-BI relation is 3 significant but 4 insignificant [1]. Although SN is an important variable in TRA and TPB, empirical evidence supporting its roles has been mixed [21,22]. So we think SN-BI is an important relation in TAM research but more deeply and widely studies should be done.

Prior IS research suggested that PBC might be a determinant of PEOU [23]. In our re-search, $\mathrm{PBC}$ - PEOU is consistent positive significant which validates the hypothesis above. PBC - BI is an important relation in TPB [11], an indirect effect through $\mathrm{BI}$ is based on the notion that $\mathrm{PBC}$ will have a motivating influence based on an individual's assessment of likelihood of success. Though our research, this effect is supported.

Perceived Enjoyment is an important intrinsic motivation variable which is seen as a determinant of system-specific perceived ease of use [24]. Our result shows that, Enjoyment actually has significant effect on PEOU (3:1). But prior researches believed Enjoyment -PEOU relation changes over time. With increasing experience, PEOU is expected to reflect the unique attributes of enjoyment as it relates to the user-system interaction [24]. We also find Enjoyment has positive significant effect on AT (4: 0), lots of previous researches support this relation, Heijden added PU and verified that it positively affected AT and BI towards personal website adoption [25]. Moon \& Kim's study showed that intrinsic motivation was positively related to attitude towards using the Web [26].

Some researchers believe there are no relationships between computer anxiety and computer-based performance $[27,28,29,30]$. But others found consistent relations between them. In our research, Anxiety has consistent significant negative effect on PU and PEOU. This consistent relationship is partly due to its independence of prior experience and gender [31], Self Efficacy Theory also conceives Experience and Anxiety as independent factors. So we think that Anxiety has significant negative effect on USE through PU and PEOU.

Agarwal \& Prasad asserted a positive relationship between an individual's prior compatible experiences and the new information technology acceptance [32]. They found that PU and PEOU non-trivially contributed in mediating the effects of compatibility to attitude. However, we only found positive relation between Compatibility and PEOU, Compatibility-PU relationship is inconsistent.

In some special areas like Internet tax-filing [33] and mobile banking [34], PC (Perceived Credibility) is one of the most important factors affecting the use intention, so in this kind of area, relations of PC - BI and PC - PU is concerned a lot $[33,19$, 35], and we find both of the relations are positive significant.

\section{FUTURE RESEARCHES}

In the previous study, relationships among TAM structure were analyzed [1], this article follows that study and further researches the relationships between new 
variables and classical TAM structure. In future, more intentions will be paid on the effects of control variables in extended TAM. These three researches will exhibit a panoramic view of the TAM research domain and provide theoretical and practical support for further studies.

\section{REFERENCES}

1. J. Qi, Y. Li, and S. Shi, Adoption of IS: Theoretical development and practices in China, in CNAIS 2006 Symposium on IT/IS Adoption (Chengdu, China, 2006).

2. Y.K. Patrick, P. Chaua, and Hu. Jen-Hwa, Investigating Healthcare Professionals' Decisions to Accept Telemedicine Technology: An Empirical Test Of Competing Theories, Information \& Management. Volume 39, pp.297-311, (2002).

3. S.S. Liaw, Understanding User Perceptions of World-Wide Web Environments, Journal of Computer Assisted Learning. Volume 18, pp.137-148, (2002).

4. C. Shyong and O.J.Y. Lai, Gender Differences in Perceptions and Relationships Among Dominants of E-Learning Acceptance, Computers In Human Behavior. Volume 22, pp.816-829, (2006).

5. H. Sun and P. Zhang, The role of moderating factors in user technology acceptance, Int. J. Human-Computer Studies. Volume 64, pp.53-78, (2006).

6. F.D. Davis, Perceived usefulness, perceived ease of use, and user acceptance of information technologies, MIS Quarterly. Volume 13, Number 3, pp.319-340, (1989).

7. V. Venkatesh and F.D. Davis, A model of the antecedents of perceived ease of use: development and test, Decision Sciences. Volume 27, Number 3, pp.451-481, (1996).

8. A. Bandura, Self-efficacy: Toward a unifying theory of behavioral change, Psychological Review. pp. 191-215, (1977).

9. M. Fishbein and I. Ajzen, Belief, Attitude, Intention and Behavior: An Introduction to Theory and Research (Addison-Wesley, Reading, MA, 1975).

10. D.R. Compeau and C.A. Higgins, Computer Self-Efficacy: Development of a Measure and Initial Test, MIS Quarterly. Volume 19 Number 2, pp.189-221, (1995).

11. I. Ajzen, From intentions to actions: a theory of planned behavior, in J.A.J.K., Action Control: From Cognition to Behavior, eds. Beckmann (Springer: Verlag, New York, 1985), pp.11-39.

12. F.D. Davis, R.P. Bagozzi, and P.R. Warshaw, Extrinsic and intrinsic motivation to use computers in the workplace, Journal of Applied Social Psychology. Volume 22, pp. 1111-1132, (1992).

13. B.H. Loyd and C.P. Gressard, Reliability and factorial validity of computer attitude scales, Educational and Psychological Measurement. Volume 44, pp.501-505, (1984).

14. E.M. Rogers and F.F. Shoemaker, Communication of Innovations, 2nd (New York, 1971).

15. Y.M. Yi, D.J. Jackson, S.J. Park, and C.J. Probst, Understanding information technology acceptance by individual professionals: Toward an integrative view, Information \& Management. Volume 43, pp.350-363, (2006).

16. H.H. Kelley and J.W. Thibaut, Interpersonal Relations: $A$ Theory of Interdependence (Wiley: New York, 1978).

17. H.H. Kelley, Personal Relationships: Their Structure and Processes (Lawrence Erlbaum Associates: Mahwah, NJ, 1979).

18. V. Venkatesh and F.D. Davis, A theoretical extension of the technology acceptance model: Four longitudinal field studies, Management Science. Volume 46, pp.186-204, (2000). 
19. I.L. Wu and J. Chen, An extension of Trust and TAM model with TPB in the initial adoption of on-line tax: An empirical study, Int. J. Human-Computer Studies. Volume 62, pp.784-808, (2005).

20. O. Sangjo, A. Joongho, and K. Beomsoo, Adoption of broadband Internet in Korea: the role of experience in building attitudes, Journal of Information Technology. Volume 18, pp.267-280, (2003).

21. E. Karahanna, D.W. Straub, and N.L. Chervany, Information technology adoption across time: a cross-sectional comparison of pre-adoption and post-adoption beliefs, $M I S$ Quarterly. Volume 23, Number 2, pp.183-213, (1999).

22. K. Mathieson, Predicting user intentions: comparing the technology acceptance model with the theory of planned behavior, Information Systems Research. Volume 2, Number3, pp.173-191, (1991).

23. V. Venkatesh, Determinants of perceived ease of use: integrating control, intrinsic motivation, and emotion into the technology acceptance model, Information Systems Research. Volume 11, Number 4, pp.342-365, (2000).

24. M. Igbaria, J. Iivari, and H. Maragahh, Why do individuals use computer technology? A Finnish case study, Information and Management. Volume 29, pp.227-238, (1995).

25. H. Heijden, Factors influencing the usage of websites: the case of a generic portal in The Netherlands, Information and Management. Volume 40, Number 6, pp.541-549, (2003).

26. J.W. Moon, Y.G. Kim, Extending the TAM for a World-Wide-Web context, Information and Management. Volume 38, Number 4, pp.217-230, (2001).

27. M.C. Kernan and G.S. Howard, Computer anxiety and computer attitudes: An investigation of construct and predictive validity issues, Educational and Psychological Measurement. Volume 50, pp.681-690, (1990).

28. C.F. Munger and B.H. Loyd, Gender and attitudes towards computers and calculators: The relationship to math performance, Journal of Educational Computing Research. Volume 5, pp.167-177, (1989).

29. B. Szajna, An investigation into the predictive validity of computer anxiety and computer attitude, Educational and Psychological Measurement. Volume 54, pp.926-934, (1994).

30. B. Szajna and J.M. Mackay, Predictors of learning performance in a computer-user training environment: A path-analytic study, International Journal of Human Computer Interaction. Volume 7, pp.361-369, (1995).

31. B. Whitely, Gender differences in computer related attitudes. It depends on what you ask, Computers in Human Behavior. Volume 12, pp.275-289, (1996).

32. R. Agarwal and J. Prasad, Are individual differences germane to the acceptance of new information technologies, Decision Sciences. Volume 30, Issue 2, pp. 361-391, (1999).

33. I.C. Chang, Y. Li, W. Hung, and H.G. Hwang, An empirical study on the impact of quality antecedents on tax payers' acceptance of Internet tax-filing systems, Government Information Quarterly. Volume 22, pp.389-410, (2005).

34. P. Luarn and H.H. Lin, Towards an understanding of the behavioral intention to use mobile banking, Computers in Human Behavior. Volume 21, pp.873-891, (2005).

35. Y. Wang, The adoption of electronic tax filing systems: an empirical study, Government Information Quarterly. Volume 20, pp.333-352, (2002).

36. A.l. Gahtani, S. Said, and M. King, Attitudes, satisfaction and usage: factors contributing to each in the acceptance of information technology, Behaviour and Information Technology. Volume 18, No. 4, pp. 277-297, (1999).

37. D. Compeau, C.A. Higgins and S. Huff, Social cognitive theory and individual reactions to computing technology: a longitudinal study, MIS Quarterly. Volume 23, No. 2, p.145$158,(1999)$.

38. M.J. Brosnan, Modeling technophobia: a case for word processing, Computers in Human Behavior. Volume 15, pp. 105-121, (1999). 
39. P. Roberts and R. Henderson, Information technology acceptance in a sample of government employees: a test of the technology acceptance model, Interacting with Computers. Volume 12, pp. 427-443, (2000).

40. V. Venkatesh and M. G. Morris, Why Don't Men Ever Stop to Ask for Directions? Gender, Social Influence, and Their Role in Technology Acceptance and Usage Behavior, MIS Quarterly. Volume 24, Number. 1, pp.115-139, (2000).

41. J.Y.L. Thong, W. Hong, and K.Y. Tam, Understanding user acceptance of digital libraries: what are the roles of interface characteristics, organizational context, and individual differences, International Journal of Human-Computer Studies. Volume 57, Number 3, pp. 215-242, (2002).

42. P. Jen-Hwa Hu, T.H.K. Clark, and W.W. Ma, Examining technology acceptance by school teachers: a longitudinal study, Information \& Management. Volume 41, pp. $227-$ 241, (2003).

43. C.L. Hsu and H.P. Lu, Why do people play on-line games? An extended TAM with social influences and flow experience, Information \& Management. Volume 41, pp. 853-868, (2004).

44. E. Yoh, M. L. Damhorst, Stephen Sapp, and Russ Laczniak, Consumer adoption of the Internet: The case of apparel shopping, Psychology and Marketing. Volume 20, Issue 12, pp. 1095-1118, (2003).

45. C.K. Riemenschneider, D.A. Harrison and P.P. Mykytyn, Understanding IT adoption decisions in small business: integrating current theories, Information \& Management. Volume 40, Issue 4, pp. 269-285, (2003).

46. H.P. Shih, An empirical study on predicting user acceptance of e-shopping on the Web, Information \& Management. Volume 41, Issue 3, pp. 351-368, (2004).

47. M. Pagani, Determinants of adoption of third generation mobile multimedia services, Journal of Interactive Marketing. Volume 18, Issue 3, pp. 46-59, (2004).

48. H. Van der Heijden, User Acceptance Of Hedonic Information Systems, MIS Quarterly. Volume 28, Number 4, pp. 695-704, (2004).

49. S.Y Hung and C.M. Chang, User acceptance of WAP services: test of competing theories, Computer Standards \& Interfaces. Volume 27, Issue 4, pp. 359-370, (2005).

50. K.C.C. Yang, Exploring factors affecting the adoption of mobile commerce in Singapore, Telematics and Informatics. Volume 22, Issue 3, pp. 257-277, (2005).

51. I.L. Wu and J.L. Chen, An extension of Trust and TAM model with TPB in the initial adoption of on-line tax: An empirical study, International Journal of Human-Computer Studies. Volume 62, Issue 6, pp. 784-808, (2005).

52. J.H. Wu and S.C. Wang, What drives mobile commerce? An empirical evaluation of the revised technology acceptance model, Information \& Management. Volume 42, Issue 5, pp. 719-729, (2005).

53. D.J. Mcfarland and D. Hamilton, Adding contextual specificity to the technology acceptance model, Computers in human behavior. Volume 22, No. 3, pp. 427-447, (2006).

54. Y. Liu, Y. Chen, and C. Zhou, Exploring Success Factors for Web-based E-Government Services: Behavioral Perspective from End Users, Information and Communication Technologies. Volume 1, pp. 937- 942, (2006).

55. J. Yu, I. Ha, M. Choi, and J. Rho, Extending the TAM for a t-commerce, Information \& Management. Volume 42, Issue 7, pp. 965-976, (2005).

56. M.S. Featherman, Evaluative Criteria and User Acceptance of Internet-Based Financial Transaction Processing Systems. Ph.D Thesis, Hawaii University (2002). 


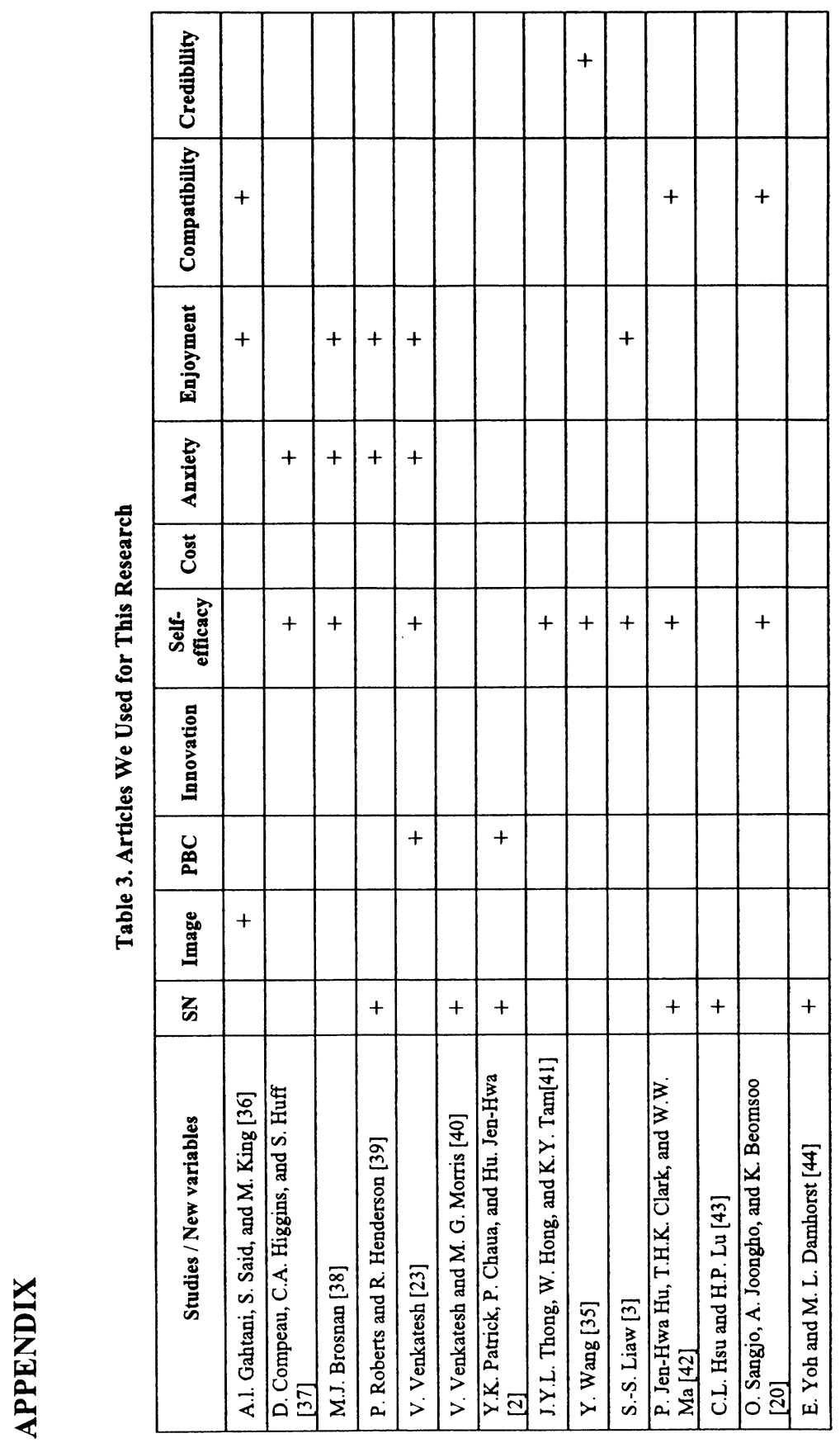




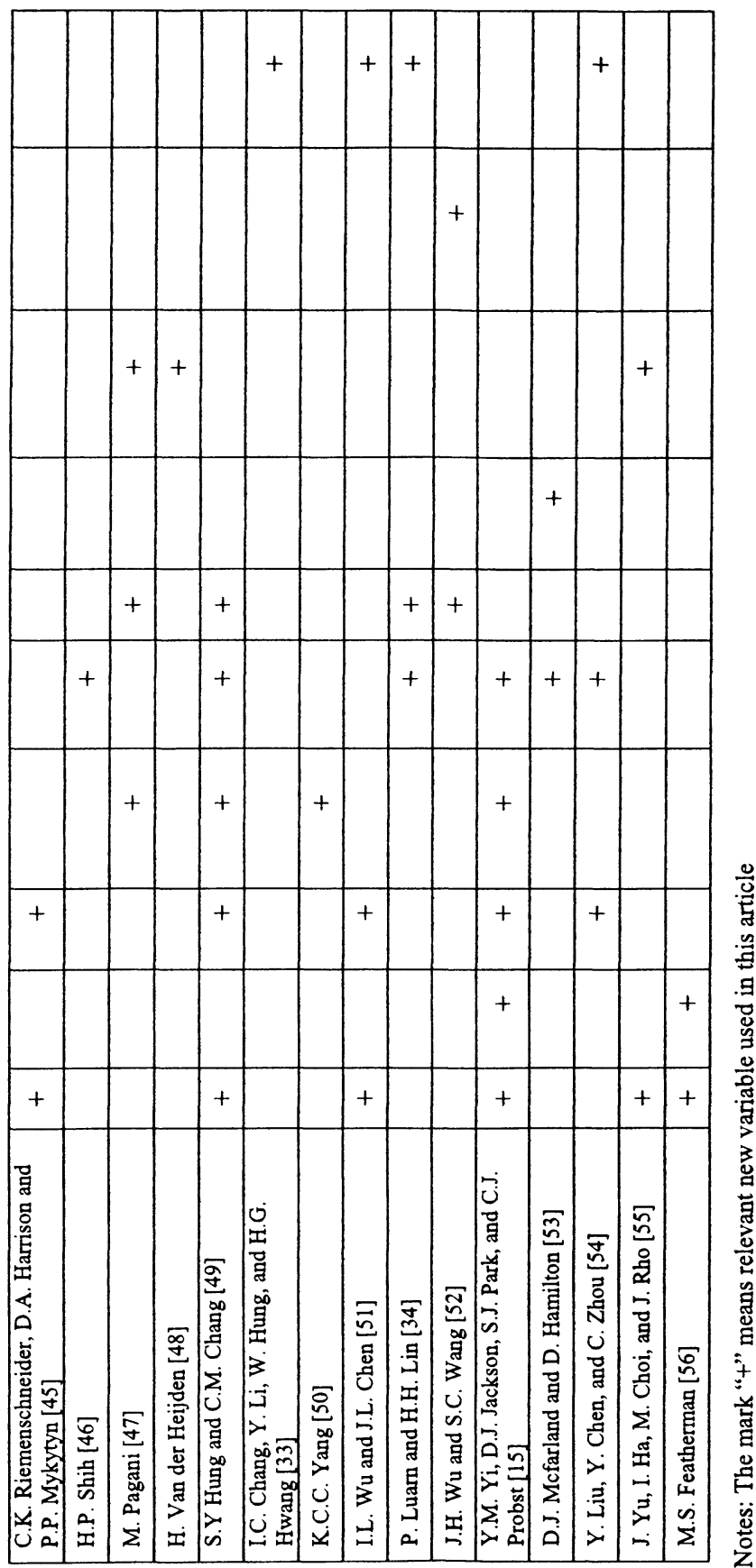

